\title{
The profile of women who consult alternative health practitioners in Australia
}

\author{
Jon Adams, David W Sibbritt, Gary Easthope and Anne F Young
}

COMPLEMENTARY and alternative medicine (CAM) is used by a substantial proportion of the population in Australia and other countries. ${ }^{1}$ Recent estimates suggest Australians spend $\$ 2.3$ billion a year on CAM. ${ }^{2}$ Thus, there is a need for information (including data on CAM consumption and users) to inform general practitioner decision-making about CAM practice and referral. ${ }^{3}$

Most research examining CAM use has been undertaken outside Australia, and has been regionally focused, ${ }^{4}$ with small numbers of participants. ${ }^{5}$ A few larger studies in the United States and Canada have identified several key variables predicting CAM use. ${ }^{6-12}$ CAM users tend to use CAM in conjunction with conventional health services, ${ }^{11}$ are more likely to be married, 8,11 be aged $35-49,{ }^{8,9}$ have a higher income $e^{8,10,11}$ and level of education, ${ }^{6,7,8,11}$ be employed full time, ${ }^{9}$ have poorer health, ${ }^{6,10}$ and are more likely to be women. ${ }^{9,11,12}$ Similar findings have been reported in the United Kingdom ${ }^{13}$ and Europe. ${ }^{14}$ The only large studies of CAM users in Australia (about 3000 participants) support these findings. ${ }^{2,15}$

CAM consumption in Australia remains under-researched. ${ }^{16}$ In particular, we know little about the profile of female CAM users. In this article, we describe the characteristics of CAM users from a nationally representative sample of more than 40000 Australian women.

\section{METHODS}

\section{Sample}

This research was conducted as part of the Australian Longitudinal Survey of Women's Health, which was designed

\section{ABSTRACT}

Objectives: To compare the characteristics of complementary and alternative medicine (CAM) users and non-users among Australian women.

Design: Cross-sectional postal questionnaire conducted during 1996, forming the baseline survey of the Australian Longitudinal Study on Women's Health.

Participants: Women aged $18-23$ years ( $n=14779), 45-50$ years $(n=14099)$ and $70-75$ years $(n=12939)$, randomly selected from the Health Insurance Commission database, with over-sampling of women from rural and remote areas of Australia.

Main outcome measures: Consultation with an alternative health practitioner in the 12 months before the survey.

Results: Women in the mid-age cohort were more likely to have consulted an alternative health practitioner in the previous year $(28 \%)$ than women in the younger cohort (19\%) or older cohort (15\%). In all age groups, CAM users were more likely than CAM non-users to reside in non-urban areas, to report poorer health, have more symptoms and illness, and be higher users of conventional health services.

Conclusions: Women in non-urban Australia are more likely to use CAM but do so in parallel with conventional health services.

MJA 2003; 179: 297-300

to investigate factors affecting the health and well-being of women over a 20-year period. Women in three age groups ("young", 18-23 years; "midage", 45-50 years; "older", 70-75 years) were randomly selected from the Health Insurance Commission database, with over-representation of women in rural and remote areas. ${ }^{17}$ The baseline survey was conducted in 1996, and the respondents (14779 young, 14099 mid-age, and 12939 older women) are representative of the national population of women in the target age groups. ${ }^{18}$

\section{Demographic characteristics}

Postcode of residence at the time of the baseline survey was used to classify resi-

See also pages 279,316

Centre for Clinical Epidemiology and Biostatistics, University of Newcastle, Newcastle, NSW.

Jon Adams, PhD, Lecturer in Health Social Science; David W Sibbritt, PhD, Lecturer in Biostatistics School of Sociology and Social Work, University of Tasmania, Hobart, TAS.

Gary Easthope, PhD, Associate Professor in Sociology

Women's Health Australia, University of Newcastle, Newcastle, NSW.

Anne F Young, PhD, Research Fellow.

Reprints will not be available from the authors. Correspondence: Dr J Adams, Centre for Clinical Epidemiology and Biostatistics, University of Newcastle, CCEB, Level 3, David Maddison Building, Royal Newcastle Hospital, Newcastle, NSW 2300. jon.adams@newcastle.edu.au

dence as urban or non-urban. Women were asked about marital status and highest completed educational qualification. Women in the young and mid-age groups were asked about employment status.

\section{Health status}

The Short-Form 36 (SF-36) Quality of Life questionnaire was used to measure health status and quality of life (physical functioning, role limitation caused by physical factors, bodily pain, general health, vitality, social functioning, role limitation caused by social factors, and mental health). ${ }^{19}$ Women were asked how often in the previous 12 months they experienced any of a list of symptoms (such as back pain, tiredness, difficulty sleeping). Women were also asked whether a doctor had ever told them that they had any of the chronic medical conditions listed, such as diabetes and hypertension. Questions about having a Pap test, hysterectomy, major personal illness or menopause (mid-age group) in the previous year, and history of smoking and alcohol use were also included.

The number of symptoms and chronic medical conditions varied for 


\begin{tabular}{|c|c|c|c|c|c|c|}
\hline & \multicolumn{2}{|c|}{ Young } & \multicolumn{2}{|c|}{ Mid-age } & \multicolumn{2}{|c|}{ Older } \\
\hline & $\begin{array}{l}\text { CAM user } \\
(n=2833)\end{array}$ & $\begin{array}{c}\text { Non-user } \\
(n=11865)\end{array}$ & $\begin{array}{l}\text { CAM user } \\
(n=3930)\end{array}$ & $\begin{array}{c}\text { Non-user } \\
(n=10042)\end{array}$ & $\begin{array}{l}\text { CAM user } \\
(n=1853)\end{array}$ & $\begin{array}{c}\text { Non-user } \\
(n=10809)\end{array}$ \\
\hline \multicolumn{7}{|l|}{ Area of residence ${ }^{\star \dagger \ddagger}$} \\
\hline Urban & $50 \%$ & $56 \%$ & $31 \%$ & $38 \%$ & $36 \%$ & $41 \%$ \\
\hline Non-urban & $50 \%$ & $44 \%$ & $69 \%$ & $62 \%$ & $64 \%$ & $59 \%$ \\
\hline \multicolumn{7}{|l|}{ Marital status } \\
\hline Married/de facto & $22 \%$ & $23 \%$ & $81 \%$ & $83 \%$ & $57 \%$ & $57 \%$ \\
\hline $\begin{array}{l}\text { Separated/ divorced/ } \\
\text { widowed }\end{array}$ & $1 \%$ & $1 \%$ & $15 \%$ & $14 \%$ & $40 \%$ & $40 \%$ \\
\hline Never married & $77 \%$ & $76 \%$ & $4 \%$ & $3 \%$ & $3 \%$ & $3 \%$ \\
\hline \multicolumn{7}{|l|}{ Education*† } \\
\hline No formal & $2 \%$ & $3 \%$ & $16 \%$ & $19 \%$ & $33 \%$ & $35 \%$ \\
\hline School only & $65 \%$ & $69 \%$ & $50 \%$ & $48 \%$ & $51 \%$ & $51 \%$ \\
\hline Trade/diploma & $22 \%$ & $17 \%$ & $20 \%$ & $19 \%$ & $12 \%$ & $10 \%$ \\
\hline Tertiary & $11 \%$ & $11 \%$ & $14 \%$ & $14 \%$ & $4 \%$ & $4 \%$ \\
\hline \multicolumn{7}{|l|}{ Employment status ${ }^{\star \dagger}$} \\
\hline Full time paid & $36 \%$ & $31 \%$ & $34 \%$ & $34 \%$ & - & - \\
\hline Part time paid & $21 \%$ & $19 \%$ & $32 \%$ & $31 \%$ & - & - \\
\hline Work without pay & $1 \%$ & 0 & $10 \%$ & $7 \%$ & - & - \\
\hline Home duties only & $4 \%$ & $7 \%$ & $14 \%$ & $18 \%$ & - & - \\
\hline Study & $28 \%$ & $31 \%$ & $1 \%$ & $1 \%$ & - & - \\
\hline Other & $10 \%$ & $12 \%$ & $9 \%$ & $9 \%$ & - & - \\
\hline
\end{tabular}

CAM $=$ Complementary and alternative medicine. CAM use is defined as consulting an alternative health practitioner in the previous 12 months. * Significant association with CAM use in young women $(P<0.005)$. †Significant association with CAM use in mid-age women $(P<0.005)$. $¥$ Significant association with CAM use in older women $(P<0.005)$.

each cohort. For the young cohort, there were 17 symptoms and 6 chronic medical conditions, in the mid cohort there were 25 symptoms and 14 chronic medical conditions, and in the older cohort there were 23 symptoms and 15 chronic medical conditions.

\section{Health service use}

The women were asked about their frequency of use in the previous 12 months (for their own health) of a range of healthcare practitioners. The list of practitioners included family doctor or another GP, hospital doctor (eg, in outpatients or casualty), a specialist doctor, and an allied health professional. Women who reported at least one consultation with an alternative health practitioner were defined as CAM users.

Other questions asked whether they had been admitted to hospital in the previous 12 months and how many different types of medication they had used in the previous four weeks prescribed by a doctor, bought without prescription, or for chronic illness.

\section{Statistical analyses}

Estimates of the proportion of women reporting use of CAM, by age cohort, were weighted (area adjusted) to correct for over-sampling from rural and remote areas. ${ }^{18}$ Within each age cohort, the demographic characteristics, health status and health service use of CAM users and non-users were compared by means of $\chi^{2}$ tests for categorical variables and $t$ tests for continuous variables.

Note that, despite non-normal distributions of some continuous variables, $t$ tests (as opposed to equivalent nonparametric tests) were used because of the large sample size. ${ }^{20}$ In addition, also in response to the large sample size and multiple comparisons, $P<0.005$ was adopted for statistical significance. ${ }^{21}$

Both weighted (area adjusted) and unweighted statistical analyses were per- formed. However, as similar results were obtained, only the unweighted results are reported for ease of interpretability. All analyses were conducted with SAS. $^{22}$

\section{RESULTS}

Australian women appear to use CAM as part of a repertoire of healthcare consumption. Response rates to the question about consulting an alternative health practitioner were $99.5 \%$ (14698/ 14779 ) for the young, $99.1 \%(13972 /$ 14099 ) for the mid-age, and $97.9 \%$ (12662/12939) for the older cohort. We estimate that CAM users constitute $19 \%, 28 \%$ and $15 \%$ of the young, midage and older cohorts, respectively (after adjustment for the over-sampling of rural women).

\section{Demographic characteristics}

Comparisons of CAM users and nonusers for demographic characteristics are shown in Box 1. In all three cohorts, CAM users were more likely to reside in non-urban areas, but there were no differences according to marital status. CAM users in the young and mid-age groups had higher levels of education and were more likely to be employed.

\section{Health status}

Box 2 compares CAM users and nonusers by health status. CAM users appear to have poorer health than nonusers. They experience a greater number of symptoms sometimes or often, and rate their physical and mental health as poorer, particularly their general health and bodily pain.

Young and mid-age CAM users reported lower vitality than non-users. Among the older women, CAM users had lower levels of physical functioning and were more limited in their ability to perform their normal activities because of their physical health. In contrast, younger CAM users were more limited by their emotional problems.

In all three cohorts, a greater proportion of CAM users had experienced a major illness in the previous 12 months. For the mid-age cohort, a greater proportion of CAM users were going through menopause. 


\section{2: Women's health status by CAM use}

\begin{tabular}{|c|c|c|c|c|c|c|}
\hline & \multicolumn{2}{|c|}{ Young } & \multicolumn{2}{|c|}{ Mid-age } & \multicolumn{2}{|c|}{ Older } \\
\hline & $\begin{array}{l}\text { CAM user } \\
(n=2833)\end{array}$ & $\begin{array}{c}\text { Non-user } \\
(n=11865)\end{array}$ & $\begin{array}{l}\text { CAM user } \\
(n=3930)\end{array}$ & $\begin{array}{l}\text { Non-user } \\
(n=10042)\end{array}$ & $\begin{array}{l}\text { CAM user } \\
(n=1853)\end{array}$ & $\begin{array}{l}\text { Non-user } \\
(n=10809)\end{array}$ \\
\hline $\begin{array}{l}\text { Mean number of symptoms } \\
(\mathrm{SD})^{\star}+\S\end{array}$ & $5(3)$ & $4(3)$ & $8(4)$ & $7(4)$ & $7(4)$ & $6(4)$ \\
\hline $\begin{array}{l}\text { Mean number of chronic } \\
\text { conditions }(\mathrm{SD})^{* \dagger}\end{array}$ & $1(1)$ & $0(1)$ & $1(1)$ & $1(1)$ & $2(2)$ & $2(2)$ \\
\hline \multicolumn{7}{|c|}{ Mean score on SF-36 dimensions (SD) } \\
\hline General health ${ }^{\dagger \ddagger}$ & $64(22)$ & $69(20)$ & $70(21)$ & $73(20)$ & $64(22)$ & $66(22)$ \\
\hline Physical functioning $\ddagger \S$ & $90(15)$ & $90(16)$ & $84(19)$ & $86(18)$ & $61(26)$ & $63(26)$ \\
\hline Bodily pain ${ }^{\dagger £ \S}$ & $68(23)$ & $76(21)$ & $65(24)$ & $73(23)$ & $59(26)$ & $66(27)$ \\
\hline Role: physical $^{\dagger \neq \S}$ & $77(34)$ & $84(29)$ & $74(38)$ & $82(33)$ & $52(43)$ & $59(42)$ \\
\hline Role: emotional $\left.\right|^{\dagger \ddagger \S}$ & $65(39)$ & $72(37)$ & $74(38)$ & $79(35)$ & $73(38)$ & $76(37)$ \\
\hline Mental health ${ }^{\dagger \ddagger \S}$ & $66(19)$ & $69(18)$ & $71(18)$ & $73(18)$ & $75(17)$ & $77(17)$ \\
\hline Social functioning ${ }^{\dagger \neq \S}$ & $72(24)$ & $77(23)$ & $79(25)$ & $83(23)$ & $78(27)$ & $82(25)$ \\
\hline Vitality $\ddagger \S$ & $53(20)$ & $58(20)$ & $56(22)$ & $60(21)$ & $58(21)$ & $60(21)$ \\
\hline $\begin{array}{l}\text { Major personal illness in } \\
\text { previous year }^{\dagger \S}\end{array}$ & $15 \%$ & $8 \%$ & $12 \%$ & $9 \%$ & $17 \%$ & $13 \%$ \\
\hline Menopause in previous year ${ }^{\ddagger}$ & - & - & $39 \%$ & $34 \%$ & - & - \\
\hline Current smokers ${ }^{\ddagger}$ & $30 \%$ & $31 \%$ & $15 \%$ & $19 \%$ & $6 \%$ & $7 \%$ \\
\hline Consume alcohol at risk levels ${ }^{\ddagger}$ & $25 \%$ & $25 \%$ & $6 \%$ & $7 \%$ & $4 \%$ & $4 \%$ \\
\hline \multicolumn{7}{|c|}{$\begin{array}{l}\text { CAM = Complementary and alternative medicine. CAM use is defined as consulting an alternative health } \\
\text { practitioner in the previous } 12 \text { months. }{ }^{*} \text { Number of possible symptoms or chronic conditions varies for age } \\
\text { cohorts. † Significant association with CAM use in young women }(P<0.005) \text {. ₹ Significant association with } \\
\text { CAM use in mid-age women }(P<0.005) \text {. } \S \text { Significant association with CAM use in older women }(P<0.005) \text {. } \\
\text { A non-parametric equivalent of the } t \text { test (Wilcoxon test) was also used to compare CAM users and non-users } \\
\text { for the number of symptoms, number of chronic conditions and the SF-36 dimensions. Siimilar results were } \\
\text { obtained in all comparisons. }\end{array}$} \\
\hline
\end{tabular}

There were no differences in smoking and alcohol consumption in the younger and older cohorts, but mid-age CAM users were less likely than non-users to be smokers or drink alcohol at risk levels.

\section{Use of health services}

Box 3 shows the use of health services. Compared with non-users, CAM users were more frequent visitors to GPs, outpatient/casualty departments and specialists. Except in the mid-age cohort, a greater proportion of CAM users were admitted to hospital in the previous 12 months.

Mid-age and older CAM users were more likely than non-users to have had a hysterectomy and to have had a recent Pap test.

Although there were no differences in the use of prescription medications, there were striking differences in the use of non-prescription medications, particularly among the older women. Overall rates of use of non-prescription medications were much higher in the younger and mid-age cohorts than in the older cohort. In the older cohort, CAM users were more likely to use medication to help them sleep, whereas in the young cohort, CAM users were more likely to be taking medication for a chronic illness.

\section{DISCUSSION}

This study is the largest examination of CAM users in the world to date. It is also the first national research to focus on CAM consumption in relation to women's health and the first to chart the profile of female CAM users across Australia.

The study reveals that CAM use is not restricted to a particular subgroup of women in Australia. CAM use differed by age group, with mid-age women more likely than their younger or older counterparts to be CAM users. CAM users were more likely than non-users to live in non-urban areas, have experienced a major illness, have more symptoms and be more limited by their health. They were more likely to report taking medication for chronic illness, and there was a strong relation between bodily pain and use of CAM. These characteristics are similar to those found in more targeted studies of CAM use. ${ }^{2,8}$

Previous studies have shown that most CAM use is integrated into care when conventional treatments have proven ineffective or undesirable. ${ }^{12}$ Similarly, our findings show women in Australia do not use CAM to replace conventional treatment. On the contrary, these women are high users of GP, specialist and hospital services. These findings suggest women pragmatically select treatments from the different options to best fit particular medical and health problems.

Our results do not enable us to determine whether women use CAM when conventional treatments have proven ineffective or undesirable, or whether they use CAM to complement contemporaneous orthodox treatment.

In either case, the use of both CAM and conventional treatments is important for those providing primary medical care. There is potential for drug interactions between conventional medicines and some complementary treatments. ${ }^{23}$ Patient safety is jeopardised because many CAM users do not inform their medical practitioner about their CAM use $^{8}$ and GPs underestimate their patients' use of other medicines. ${ }^{3,7}$

The interpretation of our findings is limited by several survey design issues. First, we defined CAM use as consultation with an alternative health practitioner, and did not include the use of self-prescribed CAM medications, although this is considerably more extensive than the use of alternative health practitioners. $^{2}$ Our definition may have led to the under-reporting of CAM use, although it is in line with that used in previous CAM research. ${ }^{4,10}$

In addition, we did not define the therapists listed, and provided only a few examples, including chiropractor, naturopath, acupuncturist and herbalist. Respondents may have different interpretations of the term "alternative health practitioner" and may have var- 


\section{3: Women's health service utilisation by CAM use}

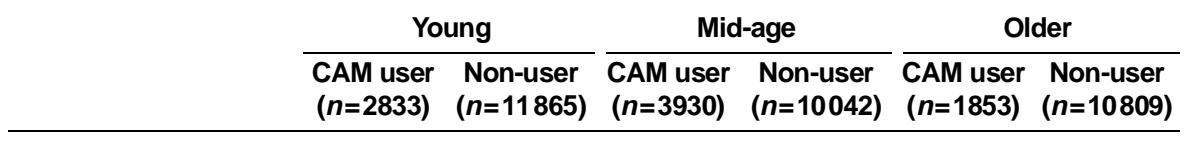

Mid-age

Older

Number of GP visits

$\begin{array}{lrrrrrr}0^{*}+ & 4 \% & 7 \% & 7 \% & 10 \% & 4 \% & 4 \% \\ 1-2^{*}+ & 25 \% & 33 \% & 34 \% & 39 \% & 14 \% & 16 \% \\ 3-4^{*}+ & 28 \% & 28 \% & 27 \% & 25 \% & 25 \% & 27 \% \\ 5-6^{*}+ & 20 \% & 17 \% & 16 \% & 13 \% & 24 \% & 23 \% \\ \geqslant 7^{* \dagger} & 23 \% & 15 \% & 16 \% & 13 \% & 33 \% & 30 \%\end{array}$

Number of outpatient/casualty visits

$\begin{array}{lrrrrrr}0^{*}+ & 68 \% & 75 \% & 82 \% & 85 \% & 75 \% & 79 \% \\ 1-2^{*}+ & 24 \% & 19 \% & 14 \% & 11 \% & 15 \% & 13 \% \\ \geqslant 3^{* \dagger} & 8 \% & 5 \% & 4 \% & 4 \% & 10 \% & 8 \%\end{array}$

Number of specialist visits

\begin{tabular}{|c|c|c|c|c|c|c|}
\hline $0^{* \dagger \ddagger}$ & $63 \%$ & $72 \%$ & $55 \%$ & $61 \%$ & $42 \%$ & $49 \%$ \\
\hline $1-2^{* \dagger \ddagger}$ & $23 \%$ & $19 \%$ & $29 \%$ & $26 \%$ & $31 \%$ & $29 \%$ \\
\hline$\geqslant 3^{* \dagger \ddagger}$ & $14 \%$ & $9 \%$ & $16 \%$ & $13 \%$ & $27 \%$ & $22 \%$ \\
\hline Hospital stay* ${ }^{\star}$ & $21 \%$ & $18 \%$ & $17 \%$ & $16 \%$ & $27 \%$ & $23 \%$ \\
\hline Hysterectomy ${ }^{\dagger \ddagger}$ & - & - & $25 \%$ & $22 \%$ & $40 \%$ & $33 \%$ \\
\hline $\begin{array}{l}\text { Pap test in past } 2 \text { years }{ }^{\dagger \ddagger} \\
\text { (no hysterectomy) }\end{array}$ & - & - & $85 \%$ & $79 \%$ & $44 \%$ & $34 \%$ \\
\hline $\begin{array}{l}\text { Prescription } \\
\text { medications }\end{array}$ & $60 \%$ & $57 \%$ & $53 \%$ & $52 \%$ & $82 \%$ & $82 \%$ \\
\hline Medication for nerves ${ }^{\dagger}$ & - & - & $8 \%$ & $6 \%$ & $14 \%$ & $12 \%$ \\
\hline $\begin{array}{l}\text { Medication to help } \\
\text { sleep }^{\dagger \neq}\end{array}$ & - & - & $9 \%$ & $7 \%$ & $21 \%$ & $17 \%$ \\
\hline $\begin{array}{l}\text { Medication for chronic } \\
\text { illness* }\end{array}$ & $11 \%$ & $7 \%$ & $20 \%$ & $19 \%$ & $38 \%$ & $36 \%$ \\
\hline $\begin{array}{l}\text { Use non-prescription } \\
\text { medications }{ }^{* \dagger \neq}\end{array}$ & $68 \%$ & $58 \%$ & $68 \%$ & $56 \%$ & $51 \%$ & $34 \%$ \\
\hline
\end{tabular}

CAM $=$ Complementary and alternative medicine. CAM use is defined as consulting an alternative health practitioner in the previous 12 months. * Significant association with CAM use in young women $(P<0.005)$. † Significant association with CAM use in mid-age women $(P<0.005)$. $¥$ Significant association with CAM use in older women $(P<0.005)$.

ied in the range of therapists they included under this heading.

These limitations are principally because our research was a sub-study taken from a larger project, which was not primarily designed to determine CAM use. Given these limitations, it is important that further research explore the relation between CAM use and women's health issues.

\section{COMPETING INTERESTS}

\section{None identified.}

\section{ACKNOWLEDGEMENTS}

The Australian Longitudinal Study on Women's Health, which was conceived and developed by groups of interdisciplinary researchers at the Universities of Newcastle and Queensland, is funded by the Australian Department of Health and Ageing. We thank all participants for their valuable contribution to this project.

\section{REFERENCES}

1. Harris $P$, Rees R. The prevalence of complementary and alternative medicine use among the general population: a systematic review of the literature. Complement Ther Med 2000; 8: 88-96.

2. MacLennan A, Wilson D, Taylor A. The escalating cost and prevalence of alternative medicine. Prev Med 2002; 35: 166-173.

3. Pirotta M, Cohen M, Kotsirilos V, Farish S. Complementary therapies: have they become accepted in general practice? Med J Aust 2000; 172: 105-109.

4. Wolsko P, Eisenberg D, Davis R, et al. Insurance coverage, medical conditions and visits to alternative medicine providers: results of a national survey. Arch Intern Med 2002; 162: 281-285.

5. Berg M, Arnetz B. Characteristics of users and nonusers of alternative medicine in dermatologic patients attending a university hospital clinic. J Altern Complement Med 1998; 4: 277-279.
6. Astin JA. Why patients use alternative medicine: results of a national study. JAMA 1998; 279: 15481553.

7. Eisenberg D, Kessler R, Foster C, et al. Unconventional medicine in the United States: prevalence, costs and patterns of use. N Engl J Med 1993; 328: 246-252.

8. Eisenberg D, Davis R, Ettner S, et al. Trends in alternative medicine use in the United States, 19901997: results of a follow-up national survey. JAMA 1998; 280: 1569-1575.

9. Kelner M, Wellman B. Health care and consumer choice: medical and alternative therapies. Soc Sci Med 1997; 45: 203-212.

10. Millar W. Use of alternative health practitioners by Canadians. Can J Public Health 1997; 88: 154-158.

11. $\mathrm{Ni} \mathrm{H}$, Simile $\mathrm{C}$, Hardy A. Utilization of complementary and alternative medicine by United States adults: results from the 1999 national health interview survey. Med Care 2002; 40: 353-358.

12. Wiles J, Rosenberg M. "Gentle caring experience" Seeking alternative health care in Canada. Health Place 2001; 7: 2209-2224.

13. Thomas K, Nicholl J, Coleman P. Use and expenditure on complementary medicine in England: a population based survey. Complement Ther Med 2001; 9: 2-11.

14. Vaskilampi T, Merilainen $P$, Sinkkonen $S$. The use of alternative treatments in the Finnish adult population. In: Lewith G, Aldridge D, editors. Clinical research methodology for complementary therapies. London: Hodder and Stoughton, 1993.

15. MacLennan A, Wilson D, Taylor A. Prevalence and cost of alternative medicine in Australia. Lancet 1996; 347: 569-573.

16. Wilkinson J, Simpson M. High use of complementary therapies in a New South Wales rural community. Aust J Rural Health 2001; 9: 166-171.

17. Brown WJ, Bryson L, Byles JE, et al. Women's Health Australia: recruitment for a national longitudinal cohort study. Women Health 1998; 28: 23-40.

18. Brown WJ, Dobson AJ, Bryson L, Byles JE. Women's Health Australia: on the progress of the main study cohorts. J Womens Health Gend Based Med 1999; 8: 681-688.

19. Ware JE, Snow KK, Kosinski M, et al. SF-36 Health survey manual and interpretation guide. Boston, MA: Health Institute, New England Medical Centre, 1993.

20. Armitage P, Berry G. Statistical methods in medical research. 2nd ed. Oxford: Blackwell, 1987.

21. Glymour C, Madigan D, Pregibon D, Smyth P. Statistical themes and lessons for data mining. Data Mining Knowl Discov 1997; 1: 11-28.

22. SAS [computer program]. Version 8.2. Cary, NC: SAS Institute, 1999.

23. Drew A, Myers S. Safety issues in herbal medicine: implications for the health professionals. Med J Aust 1997; 166: 538-541.

(Received 21 Nov 2002, accepted 14 Aug 2003) 